\title{
Pelatihan Pengumandangan Adzan dan Iqomah di Masjid Al-Iman, Desa Pisang Baru, Kecamatan Bumi Agung, Kabupaten Waykanan, Lampung
}

\author{
Wahyu Stiawan $^{a \star}$, Hendri Noperi ${ }^{\mathrm{b}}$, Husnul Fatarib ${ }^{a}$ \\ anstitut Agama Islam Negeri Metro, Jl. Ki Hajar Dewantara No.15A, Iringmulyo, Kec. Metro \\ Tim., Kota Metro, Lampung 34112 Indonesia \\ bUPBJJ-UT Bandar Lampung, JL Soekarno-Hatta, No. 108 B, Rajabasa, 35144, Rajabasa, \\ Kec. Rajabasa, Kota Bandar Lampung, Lampung 35142 Indonesia \\ Email Korespondensi: wahyustiawan1991@gmail.com
}

\section{Diterima: Januari 2020; Revisi: Mei 2020; Diterbitkan: Mei 2020}

\begin{abstract}
Abstrak
Adzan dan iqomah merupakan bagian dari dakwah, yang berisi kalimat tauhid dan adzan untuk hadir dalam shalat berjamaah. Adzan sangat penting sebagai tanda bahwa masuknya waktu shalat telah tiba, sedangkan iqomah sebagai tanda shalat akan segera dilaksanakan. Pengumuman adzan dan iqomah tidak bisa dilakukan sembarangan. Namun, anak-anak di Desa Pisang Baru belum dapat mengumandangkan adzan dengan benar sesuai dengan pengajian, dan sesuai dengan tata cara teguran. Berdasarkan hal tersebut maka perlu diadakan pelatihan pekerjaan rumah adzan dan iqomah untuk anak-anak di desa Pisang Baru. Tahap pelaksanaan kegiatan pelatihan yaitu (1) melakukan survey peserta pelatihan, (2) memberikan informasi kepada warga sekitar yang memiliki anak usia sekolah dasar untuk mengikuti pelatihan, dan (3) melaksanakan kegiatan pelatihan. Hasil kegiatan menunjukkan bahwa peserta mampu mempraktikkan adzan dan iqomah dengan baik, sehingga dapat disimpulkan bahwa kegiatan pelatihan pengumandangan azan dan iqomah berjalan dengan lancar dan sesuai yang diharapkan.
\end{abstract}

Kata Kunci: pelatihan; adzan; iqomah

\section{Adhan and Iqomah Publication Training at Al-Iman Mosque, Pisang Baru Village, Bumi Agung District, Waykanan Regency, Lampung}

\begin{abstract}
Adhan and iqomah are part of the da'wah, that contains monotheism sentences and a call to be present in the congregational prayer. Adhan is very important as a sign that the entry of prayer times has arrived, while iqomah is a sign of prayer will soon be held. Adhan and iqomah announcements cannot be done haphazardly. However, children in the village of Pisang Baru were not been able to recite the call to prayer correctly in accordance with the recitation, and are well in accordance with the procedures for admonition. Based on this, it is necessary to hold adzan and iqomah homework training for children in the Pisang Baru village. The implementation stage of the training activities are (1) conducting a survey of training participants, (2) providing information to local residents who have elementary school age children to attend training, and (3) carrying out training activities. The results of the activity showed that the participants were able to practice the call to prayer and iqomah well, so it can be concluded that the training activities for the call to prayer and iqomah were running smoothly and as expected.
\end{abstract}

Keywords: training; adhan; iqomah

How to Cite: Stiawan, W., Noperi, H., \& Fatarib, H. (2020). Pelatihan Pengumandangan Adzan dan Iqomah di Masjid Al-Iman, Desa Pisang Baru, Kecamatan Bumi Agung, Kabupaten Waykanan, Lampung. Lumbung Inovasi: Jurnal Pengabdian kepada Masyarakat, 5(1), 30-33. doi:https://doi.org/10.36312/linov.v5i1.462

https://doi.org/10.36312/linov.v5i1.462

\section{PENDAHULUAN}

Syiar Islam di Indonesia sangat tampak secara umum, terutama syiar islam berupa ibadah-ibadah yang kita lakukan sehari-hari seperti adzan. Hal ini merupakan salah satu 
tanda sempurnanya syari'at Islam yaitu memberi dorongan kepada ummat untuk melaksanakan ibadah dengan menyebutkan keutamaan ibadah tersebut (Syarif, 2016). Menurut Imam Qurthubi, adzan mengandung makna akidah, karena ia dimulai dengan takbir dan memuat tentang wujud Allah SWT dan kesempurnaan-Nya, kemudian diiringi dengan tauhid, lalu menetapkan kerasulan Muhammad Saw, serta seruan untuk patuh dan taat sebagai akibat pengakuan risalah karena ia tidak mungkin dikenal kecuali dengan tuntunan Rasulullah, setelah itu, diserukannya kemenangan yaitu, kebahagiaan yang kekal lagi abadi, yang terdapat isyarat mengenai kampung akhirat. Kemudian beberapa kali diulang sebagai penegasan dan penguatan (Gaffar, 2017). Makna akidah tersebut secara otomatis akan tertanam pada diri seseorang yang mengumandangkan adzan.

Orang yang mengumandangkan adzan disebut muadzin. Adzan mulai disyariatkan pada tahun kedua Hijriah. Pada saat Nabi Muhammad SAW mengumpulkan para sahabat untuk memusyawarahkan bagaimana cara memberitahu masuknya waktu salat dam mengajak orang ramai agar berkumpul ke masjid untuk melakukan salat berjamaah (Pjriah \& Mulyadi, 2014).Menjadi seorang muadzin bukanlah perkara mudah harus memenuhi syaratsyarat tertentu (Chandra, 2019). Akan tetapi, pada saat-saat tertentu seseorang yang mengumandangkan adzan diperbolehkan dengan kemampuan sudah menghafal lafadz adzan. Hal ini sebagaimana di kisahkan oleh kegigihan dan ketabahan seorang budak yang bernama Bilal bin Rabbah sangat memberikan sebuah pelajaran bagi manusia khususnya bagi kaum Muslimin di seluruh dunia bahwa sosok budak yang terus disiksa dengan kegigihannya dia menjadi seorang muslim yang taat dan selalu berada di samping Rasulullah Shalallahu 'Alaihi Waasallam sampai Rasulullah wafat (meninggal) yang kemudian menjadi kepercayaan Rasulullah dalam mengumandangkan seruan Adzan, sehingga cikal awal mula pengumandang Adzan yang selalu dikumandangkan oleh kaum yang beragama Islam di seluruh alam semesta sampai hari kiamat setiap lima kali dalam sehari itu adalah Bilal bin Rabbah (Pjriah \& Mulyadi, 2014).

Seiring perkembangan zaman, adzan telah di siarkan diberbagai media elektronik seperti smart phone, televisi, dan radio (Dimiyati \& Basith, 2018). Hal ini juga membuktikan bahwa banyak sekali muadzin-muadzin yang memiliki suara yang indah, dengan pelafalan adzan yang baik dan benar. Selain itu, adanya siaran adzan di berbagai media elektronik, mempermudah semua orang untuk mengetahui waktu masuk shalat telah tiba. Muadzinmuadzin masjid yang kemudian mengumandangkan adzan untuk mengumpulkan jamaah shalat.

Daerah Pisang Baru, di sekitar masjid Al-Iman, mayoritas penduduk berprofesi sebagai guru dan bekerja di kantor pemerintahan. Pelaksanaan shalat berjamaah di masjid Al-iman hanya dilakukan setiap kali ada yang mengumandangkan adzan. Shalat dhuhur dan ashar rentan sekali tidak ada shalat berjamaah karena kesibukan/belum pulang bekerja sehingga tidak ada yang berlaku sebagai muadzin. Pengurus masjid yang ada juga belum dapat menangani hal ini dikarena kesibukan profesi masing-masing. Berdasarkan masalah tersebut, perlu adanya pengkaderan sebagai muadzin di Masjid Al-Iman desa Pisang Baru, Kecamatan Bumi Agung.

Pelatihan adzan dan iqomah dapat difokuskan pada anak-anak usia sekolah dasar yang dianggap lebih efektif (Armuza, 2010). Anak-anak dapat melaksanakan tugasnya sebagai muadzin setelah pulang sekolah, terkhusus untuk shalat zhuhur dan juga shalat asar. Hal ini diharapkan menjadi solusi terkait permasalahan yang terjadi di Masjid Al-Iman supaya terlaksana shalat berjamaah lima waktu. Anak-anak dapat menjadi generasi muadzin yang mampu mengumandangkan adzan dan iqomah dengan baik dan benar.

Adapun yang harus dipahamai ketika adzan adalah mengetahui adab melaksanakan adzan menurut jumhur ulama ialah: 1) Muazin hendaknya tidak menerima upah dalam melakukan tugasnya, 2) Muazin harus suci dari hadas besar, hadas kecil, dan najis, 3) Muazin menghadap ke arah kiblat ketika mengumandangkan azan, 4) ketika membaca hayya 'ala assalah muazin menghadapkan muka dan dadanya ke sebelah kanan dan ketika membaca hayya 'ala al-falah menghadapkan muka dan dadanya ke sebelah kiri, 5) muazin memasukkan dua anak jarinya ke dalam kedua telinganya; 6) Suara muazin hendaknya nyaring;muazin tidak boleh berbicara ketika mengumandangkan adzan, 7) Orang-orang yang mendengar azan hendaklah menyahutnya secara perlahan dengan lafal-lafal yang diucapkan oleh 
muazin, kecuali pada kalimat hayya 'ala assalah dan hayya 'ala al-falah yang keduanya disahut dengan la haula wa la quwwata illa bi Allah (tidak ada daya dan kekuatan kecuali dari Allah), 8) Setelah selesai azan, muazin dan yang mendengar azan hendaklah berdoa: Allahumma rabba hazihi ad-da'wah at-tammah wa as-salati alqa'imah, ati Muhammadan alwasilah wa al-fadilah wab'ashu maqaman mahmuda allazi wa'adtahu (Wahai Allah, Tuhan yang menguasai seruan yang sempurna ini, dan salat yang sedang didirikan, berikanlah kepada Muhammad karunia dan keutamaan serta kedudukan yang terpuji, yang telah Engkau janjikan untuknya [HR. Bukhari] (Samsudin, 2016).

\section{METODE PELAKSANAAN}

Pelatihan pengumandangan adzan dan iqomah dilaksanakan di Desa Pisang Baru, Kecamatan Bumi Agung, Way Kanan, Lampung. Tahap pelaksanaan kegiatan pelatihan adzan dan iqomah adalah sebagai berikut: 1) melakukan survey peserta pelatihan untuk menetapkan kriteria anak yang dapat mengikuti pelatihan adzan, 2) memberikan informasi kepada warga sekitar yang memiliki anak usia sekolah dasar untuk mengikuti pelatihan tersebut, 3) melaksanakan kegiatan pelatihan.

Kegiatan dilaksanakan pada hari jumat-minggu, tanggal 15-17 November 2019. Pelatihan ini terdiri dari 3bagian, yaitu penyampaian materi tentang adzan dan iqomah, praktik adzan dan iqomah, menghapal do'a ketika dan setelah adzan. Peserta yang masuk dalam daftar Pelatihan Adzan dan lqomah adalah sebanyak 9 anak dengan rentang usia $8-11$ tahun.

\section{HASIL DAN PEMBAHASAN}

Kegiatan pengabdian dengan melakukan pelatihan adzan dan iqomah telah berjalan dengan baik. Tahap pelaksanaan yang pertama yaitu melakukan survey pelatihan untuk menetapkan kriteria anak yang mengikut pelatihan adzan di dasarkan pada syarat-syarat sebagai muadzin. Sebagaimana menurut pendapat (Muntoha et al., 2015) syarat menjadi muadzin diantaranya adalah memiliki bacaan yang baik, sehingga huruf adzan dibaca dengan baik dan tidak mengubah pengertiannya. Berdasarkan hal tersebut maka ditetapkan peserta pelatihan merupakan anak-anak yang memiliki rentang usia 8-11 tahun. Selain menentukan rentang usia, penentuan pelaksanaan pelatihan juga perlu mempertimbangkan aktivitas anakanak di lingkungan Masjid Al-Iman. Menurut Muntoha et al., (2015) banyaknya kegiatan pribadi maupun kemasyarakatan anak-anak yang seringkaliberbenturan dengan jadwal TPA dapat menyebabkan kendala dalam memberikan pelatihan adzan dan iqomah.

Tahap pelaksanaan kedua yaitu memberikan informasi kepada warga sekitar yang memiliki anak laki-laki berusia 8-11 tahun untuk dapat mendaftar menjadi peserta pelatihan. Informasi ini disambut baik oleh warga sekitar dan kemudian mulai mendaftarkan anakanaknya. Tahap pelaksanaan ketiga yaitu tahap melaksanakan kegiatan pelatihan adzan dan iqomah. Tahap pelatihan ini terdiri tiga bagian yaitu penyampaian materi adzan dan iqomah, praktik adzan dan iqomah, menghapal do'a ketika dan setelah adzan.

Kegiatan hari pertama yaitu penyampaian materi adzan dan iqomah, peserta terlihat sangat antusias. Hampir seluruh peserta sudah hafal lafadz adzan dan iqomah. Permasalahan yang terjadi adalah peserta sebagaian besar belum pernah menyuarakan adzan di Masjid. Berdasarkan hal tersebut maka narasumber perlu memberikan tips-tips dan motivasi kepada peserta agar dapat percaya diri dalam mengumandangkan adzan. Selain itu, narasumber juga memberikan penjelasan bagian-bagian lafadz adzan yang sering kali mengalami kesalahan dalam pelafadzan.

Kegiatan hari kedua yaitu praktik adzan dan iqomah, satu peserta tidak hadir dikarenakan sedang sakit. Peserta yang hadir mampu seluruhnya mempraktikkan adzan dan iqomah dengan baik, sehingga dapat dikatakan bahwa pelaksanaan kegiatan praktik dapat berjalan dengan lancar dan sesuai yang diharapkan. 


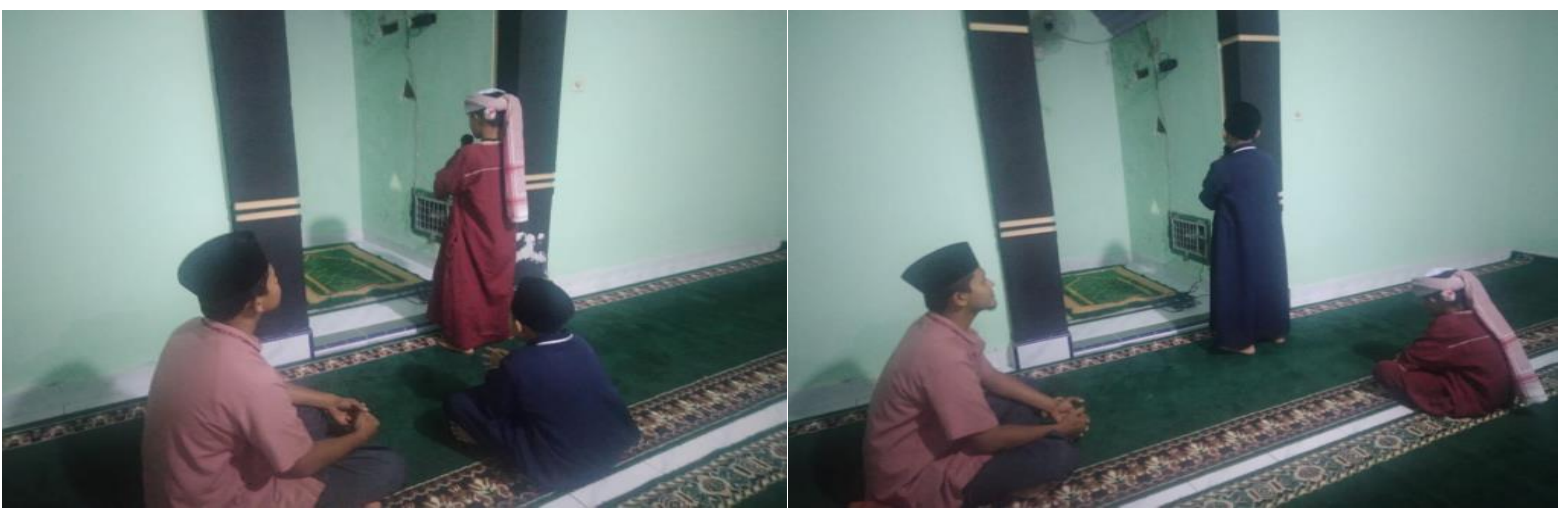

Gambar 1. Praktik Adzan dan lqomah

Kegiatan hari ketiga yaitu menghapal do'a ketika dan setelah adzan. Beberapa peserta mengalami kesulitan, akan tetapi ada juga peserta yang sudah lancar dalam do'a. Kesulitan bagi peserta dalam menghafal diatasi oleh narasumber dengan memberikan teks doa ketika dan setelah adzan.

\section{KESIMPULAN}

Pelatihan adzan dan iqomah ini tentunya tidak terbatas hanya beberapa hari saja. Dukungan orang tua dan juga dukungan pengurus masjid sangat diperlukan bagi perkembangan generasi muadzin di Masjid Al-Iman. Kendala-kendala yang dihadapi pada saat proses pelatihan dapat diminimalisir dengan kesiapan pelaksana pelatihan, pemilihan peserta pelatihan, fasilitas yang mendukung, dan pemilihan waktu pelaksanaan yang tepat.

\section{REKOMENDASI}

Pelatihan terkait doa setelah azan, zikir dan wirid-wirid setelah azan perlu dilakukan untuk lebih memperkuat kemampuan peserta di masa mendatang.

\section{DAFTAR PUSTAKA}

Armuza, A. (2010). Rahasia Dahsyatnya Adzan. Kaukaba.

Chandra, A. G. (2019). Pesan Moral Dalam Tayangan Adzan Maghrib Di RCTI. Jurnal Dakwah Dan Komunikasi, 1(1).

Dimiyati, S. M., \& Basith, A. (2018). Pengaruh Tayangan Adzan Maghrib Terhadap Ketepatan Waktu Sholat Terhadap Ibu-lbu Masyarakat Dukuh Bojong Desa Kalibuntu Kec Losari Kab Brebes. ORASI: Jurnal Dakwah dan Komunikasi, 9(1), 65-78. https://doi.org/10.24235/orasi.v9i1.2965

Gaffar, A. (2017). Azan terhadap anak yang dilahirkan. Tahdis: Jurnal Kajian IImu Al-Hadis, 8(1), 68-89. https://doi.org/10.24252/tahdis.v8i1.4007

Muntoha, Jamroni, \& Jabar, A. A. (2015). Pelatihan Pengumandangan Adzan dan lqomah di Taman Pendidikan Al-Qur'an Masjid Arofah, Dusun Bandung dan Dusun Songbanyu 1, Kecamatan Songbanyu, Gunung Kidul, Daerah Istimewa Yogyakarta. Jurnal Inovasi Dan Kewirausahaan, 4(3), 161-165.

Pjriah, S., \& Mulyadi, A. (2014). Peranan Bilal Bin Rabbah dalam Perkembangan Islam di Jazirah Arab Tahun 611 M - 641 M (Suatu Tinjauan Sejarah). Jurnal Artefak, 2(1), 1332.

Samsudin. (2016). Upaya Peningkatan Pengetahuan Sisiwa Kelas V SDN 26 Sintang Terhadap Materi Azan dan Iqomah Melalui Penggunaan Metode Demonstrasi. Vox Educasi, 7(2), 216-233.

Syarif, A. (2016). Nilai-nilai Pendidikan dalam Kalimat Azan. Al-Ishlah, 225-251. 